GA-A25611

\title{
B-DOPED Be COATINGS FOR NIF TARGET DEVELOPMENT
}

\author{
by \\ H. XU, K.A. MORENO, K.P. YOUNGBLOOD, \\ A. NIKROO, R.E. HACKENBERG, J.C. COOLEY, \\ C.S. ALFORD, S.A. LETTS
}

APRIL 2007 


\section{DISCLAIMER}

This report was prepared as an account of work sponsored by an agency of the United States Government. Neither the United States Government nor any agency thereof, nor any of their employees, makes any warranty, express or implied, or assumes any legal liability or responsibility for the accuracy, completeness, or usefulness of any information, apparatus, product, or process disclosed, or represents that its use would not infringe privately owned rights. Reference herein to any specific commercial product, process, or service by trade name, trademark, manufacturer, or otherwise, does not necessarily constitute or imply its endorsement, recommendation, or favoring by the United States Government or any agency thereof. The views and opinions of authors expressed herein do not necessarily state or reflect those of the United States Government or any agency thereof. 


\title{
B-DOPED Be COATINGS FOR NIF TARGET DEVELOPMENT
}

\author{
by \\ H. XU, K.A. MORENO, K.P. YOUNGBLOOD, \\ A. NIKROO, R.E. HACKENBERG, ${ }^{*}$ J.C. COOLEY, \\ C.S. ALFORD, ${ }^{\dagger}$ S.A. LETTS $†$
}

This is a preprint of a paper to be presented at the AVS 53rd International Symposium and Exhibition, November 11-17, 2006 in San Francisco, California and to be published in the Proceedings.

*Los Alamos National Laboratory, Los Alamos, New Mexico

tLawrence Livermore National Laboratory, Livermore, California

\author{
Work supported by the \\ U.S. Department of Energy under \\ DE-AC52-06NA27279, W-7405-ENG-36, \\ and $W-7405-E N G-48$
}

GENERAL ATOMICS PROJECT 30272 APRIL 2007 



\begin{abstract}
Sputtered beryllium and copper-doped beryllium coatings as thick as $170 \mu \mathrm{m}$ have been deposited on spherical substrates to produce hollow shells that are required as targets for inertial fusion experiments. Be coatings by magnetron sputtering achieved $\sim 95 \pm 2 \%$ bulk density consistently up to $170 \mu \mathrm{m}$ thick. Coatings on the spherical substrates exhibit the typical columnar structure throughout the entire thickness. Transmission electron microscopy (TEM) indicates the presence of sub-micron, nearly spherical voids mainly aggregated along the columnar structure and grain boundaries as well as some smaller intra-granular elongated voids. Holes have been drilled in beryllium shells produced in this manner to allow filling with deuterium (the fusion fuel). Gas retention of these shells has been examined using mass spectrometry. It appears that a fraction of the pores in the coatings are interconnected, which leads to leakage of the hollow shells. Boron-doped Be layers near the eutectic phase at a concentration of $\sim 11$ at. \%, have been added to the Be shells to significantly improve $\mathrm{D}_{2}$ gas retention of the shells. However, there remains a considerable scatter in the measured leakage.
\end{abstract}





\section{INTRODUCTION}

Beryllium is one of the preferred ablators for achieving ignition on the National Ignition Facility (NIF) because of its high density, low opacity and high thermal conductivity [1]. A graded copper-doped ablator is currently proposed for NIF due to its superior stability during implosion. Sputter coating of beryllium on a removable mandrel is one possible means of producing beryllium shells for NIF. Previous studies have demonstrated the feasibility of producing Be coatings $\leq 100 \mu \mathrm{m}$ on spherical polymer mandrels using magnetron sputtering [2-5]. However, due to the curvature of a spherical mandrel surface, sputtered atoms regularly land on the surface with an angle from the surface normal. The shadowing effect of new atoms by previous atoms on the surface for an inclined deposition may result in a coating of low density and high defect concentrations [6,7].

According to Thornton's zone model [8], magnetron sputtering produces films with microstructures categorized in four zones: zone 1, transition zone, zone 2 and zone 3 . In zone 1 , tapered or fibrous grains and voided boundaries form where the structure is influenced by the shadowing effect and roughness of the substrate surface. The transition zone is marked by dense grain boundary arrays and a film with a high dislocation density. Columnar grains evolve in zone 2 where the evolution of the structure is aided by surface diffusion processes. The transition from surface diffusion to bulk diffusion, as well as recrystallization and grain growth, leads to the formation of an equiaxed grain structure in zone 3 . Under typical magnetron sputtering conditions, the substrate temperature $\left(T_{S}\right)$ is $\sim 150^{\circ} \mathrm{C}$. The ratio of $T_{s} / T_{m}\left(T_{m}\right.$-Be melting temperature) is $\sim 0.25$, which suggests that the Be coating is in the transition zone.

Previous studies of Be coating by magnetron sputtering showed columnar grain structure with limited data on Be coating density and properties of defects [2-5]. The Be shell gas retention property was rarely studied. In a few unreported incidents, attempts to fill the Becoated shells by permeation under pressures of deuterium resulted in shells with no deuterium suggesting an impermeable Be coating. However, there are no detailed reports of the experiments. Due to the defects observed in the films [9], Be shells created by sputtering onto $\mathrm{CH}$ mandrels may not be gas retentive. In order to develop dense and gas-retentive $\mathrm{Be}$ capsules for NIF targets, we studied the Be coating properties and their related permeation characteristics. Results show that Be coatings prepared under regular magnetron sputtering conditions had very short gas retention half-life of a few minutes to a few hours for $2 \mathrm{~mm}$ diameter shells. Current NIF requirement for $\mathrm{D}_{2}$ gas retention half-life is seven days. Therefore, it is essential to develop a gas retention permeation barrier for Be capsules in order to meet the NIF requirement. 



\section{EXPERIMENTS}

Be coatings were deposited in a high vacuum chamber equipped with three $2 \mathrm{in}$. Be magnetron sputter sources and one 2 in. B sputter source, all symmetrically arranged around the substrates. The system is evacuated to a base pressure of $\sim 1 \times 10^{-6}$ Torr after overnight pumping by a $1500 \mathrm{l} / \mathrm{s}$ cryopump. The sputtering gas is high purity Ar (99.999\%). Coating was typically performed on $2 \mathrm{~mm}$ diameter plastic mandrels (20-30 $\mu \mathrm{m}$ thick) agitated by rolling or bouncing in a 2 in. diameter stainless steel pan for uniform coatings [9]. The depositions were done at a fixed pressure of Ar which ranged from 3-10 mTorr depending on the particular run. The targets-to-bounce-pan distance was set at $\sim 10 \mathrm{~cm}$.

The thickness of the Be coating on the plastic mandrel was measured by scanning electron microscopy (SEM) and x-ray radiography. The typical coating rate for three Be guns at $100 \mathrm{~W}$ is $0.4-0.5 \mu \mathrm{m} / \mathrm{h}$ on shells. We could deposit a $50 \mu \mathrm{m}$ Be coating on shells by running the guns for approximately six continuous days before replacement of the $0.25 \mathrm{in}$. thick Be targets.

Coatings were characterized using a variety of techniques to examine structure, roughness, density and composition. The film microstructure was examined by SEM and transmission electron microscopy (TEM). Be film density was measured based on the ratio of shell mass and volume. Shells were weighed using an ATI Cahn C-35 microbalance accurate to $0.3 \mu \mathrm{g}$. Since the weight of the beryllium coated shells is typically $\sim 2 \mathrm{mg}$ or higher, the error in density is well below $0.1 \%$. The accuracy of diameter measurements using x-ray radiography is $\sim 1 \mu \mathrm{m}$ for a $2 \mathrm{~mm}$ diameter shell resulting in a density error of $\sim 0.1 \%$. Shell thickness measurements result in considerable error in density measurements. The thickness is typically measured using $\mathrm{x}$-ray radiography [10] comprising an error $<2 \mu \mathrm{m}$, with a density error of $\sim 4 \%$.

Gas retention of Be shells was measured with a mass spectrometer (MS), which calibrated by fixed leak rate sources [11]. After Be coating, the shells were laser drilled (hole diameter 5-10 $\mu \mathrm{m}$ ) and inner plastic mandrels were burned out (400-550 ${ }^{\circ} \mathrm{C}$ for $60 \mathrm{~h}$ ) [12]. The Be shells were then loaded into a pressurized cell of deuterium and the hole sealed under pressure with epoxy. The gas retention half-life is extracted by comparing the mass spectrometer signal of the sealed shells to the fixed leak rate references. When the gas retention half-life is long, the MS signal is inversely proportional to the gas retention half-life [11]. The measured gas retention half-life was confirmed by crushing the sealed shells in a fixed volume. After crushing the shells, the volume of released gas was calculated from the rise in pressure of the fixed volume. In this way, the gas retention half-life $\left(\tau_{1 / 2}\right)$ can be directly obtained from $P=P_{0} e^{-t / \tau}$, where $\tau$ is gas retention time constant $\left(\tau_{1 / 2}=\tau \cdot \ln 2\right)$, $P_{0}$ is the fill pressure and $P$ is the measured pressure in the shell at time $t$. 



\section{RESULTS}

The Be coating microstructure under typical sputtering conditions is columnar as evidenced by SEM images. Figure 1 shows a cross sectional SEM image of a Be coating on a plastic mandrel using rolling agitation, which results in a uniform columnar structure. The majority of Be coating densities measured fall between 1.72 and $1.79 \mathrm{~g} / \mathrm{cm}^{3}$, which are 93\%-97\% of Be bulk density. The density did not show a dependence on coating thickness.

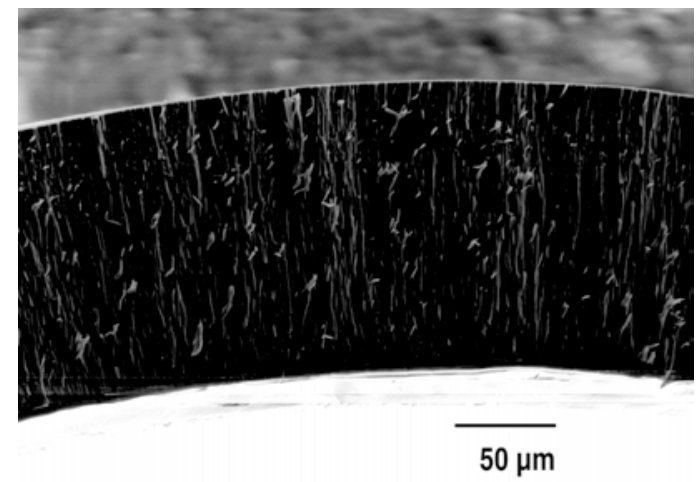

Fig. 1. SEM cross section of a $144 \mu \mathrm{m}$ thick Be coating on a plastic mandrel showing uniform columnar grains throughout.

TEM studies were conducted to help understand the Be coating microstructures and defects. Figure 2(a) shows a TEM image of a typical columnar Be coating microstructure at $\sim 95 \%$ bulk density created using a coating rate of $\sim 0.4 \mu \mathrm{m} / \mathrm{h}$. Some isolated voids along grain boundaries are shown in Fig. 2(a) (arrows). The void sizes vary, but are typically smaller than $200 \mathrm{~nm}$ diameter. Striation lines in the grains are also observed in higher resolution images as shown in Fig. 2(b). These lines are $\sim 2 \mathrm{~nm}$ wide and approximately $1 \mu \mathrm{m}$ long. As a result of bouncing agitation which deposited at higher rates $(\sim 1.5 \mu \mathrm{m} / \mathrm{h})$, we observed large voids in the coatings. As seen in Fig. 3, a low density Be coating of $\sim 80 \%$ bulk density consisted of voids larger than $500 \mathrm{~nm}$ diameter.

In order to understand the gas retention properties of the sputtered Be coatings, we tested Be shells of various thickness and under different preparation conditions. These conditions include altering the deposition pressures (3-10 mTorr), biasing the rolling/bouncing pan, interrupting the growth and pulsing oxygen into the chamber during film deposition. None of these changes altered the grain structure, and the gas retention half-life continued to be short. As summarized in the top graph of Fig. 4 , the majority of Be shells showed $\mathrm{D}_{2}$ gas retention half-lives of less than a day. Low gas retention and the characteristic void structure observed by TEM indicate that there is a direct relationship between Be columnar structure and gas leakage. 

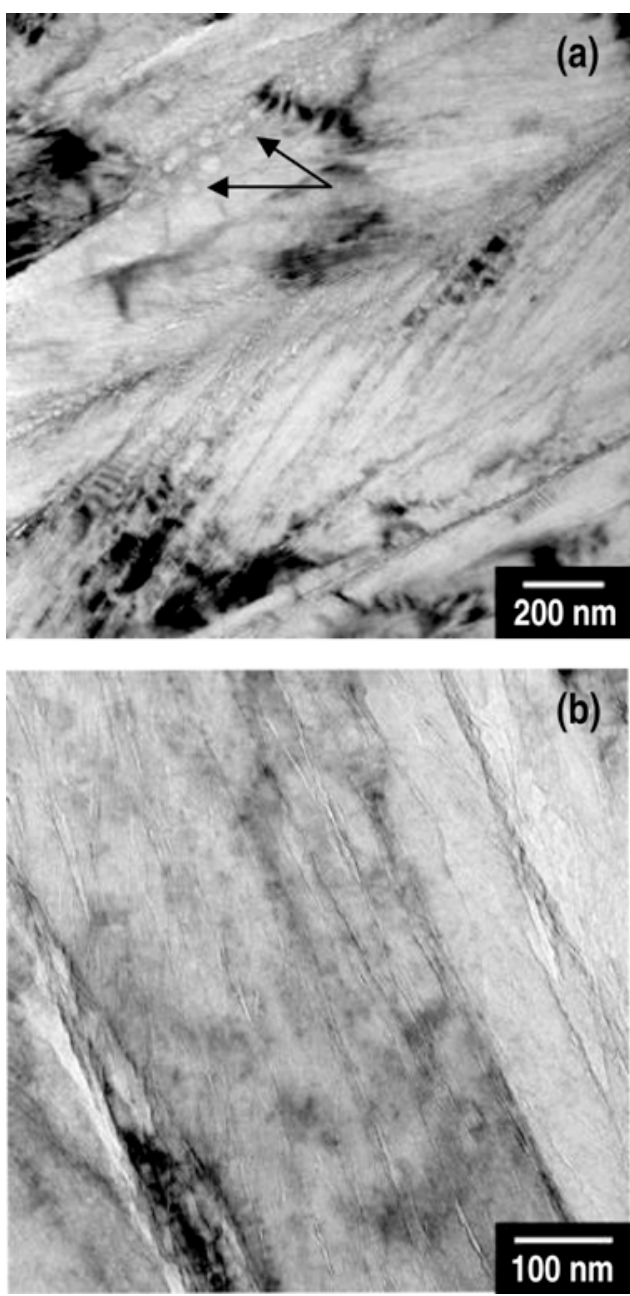

Fig. 2. (a) This TEM image shows large bubble-like voids along grain boundaries (arrows). (b) A highresolution TEM image shows intra-granular striations.

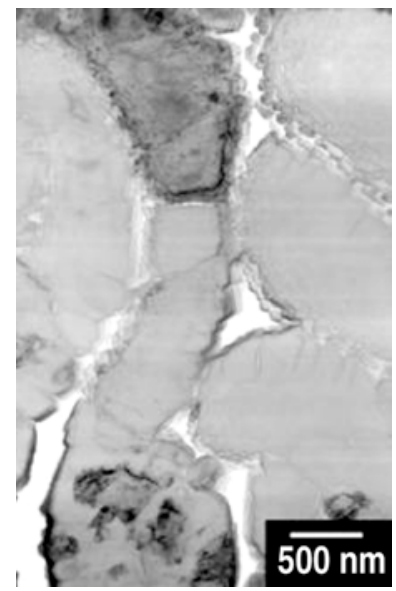

Fig. 3. A TEM image of a low-density Be coating made at a higher coating rate. The white portions feature voids of dimension larger than $500 \mathrm{~nm}$ in the coating. 


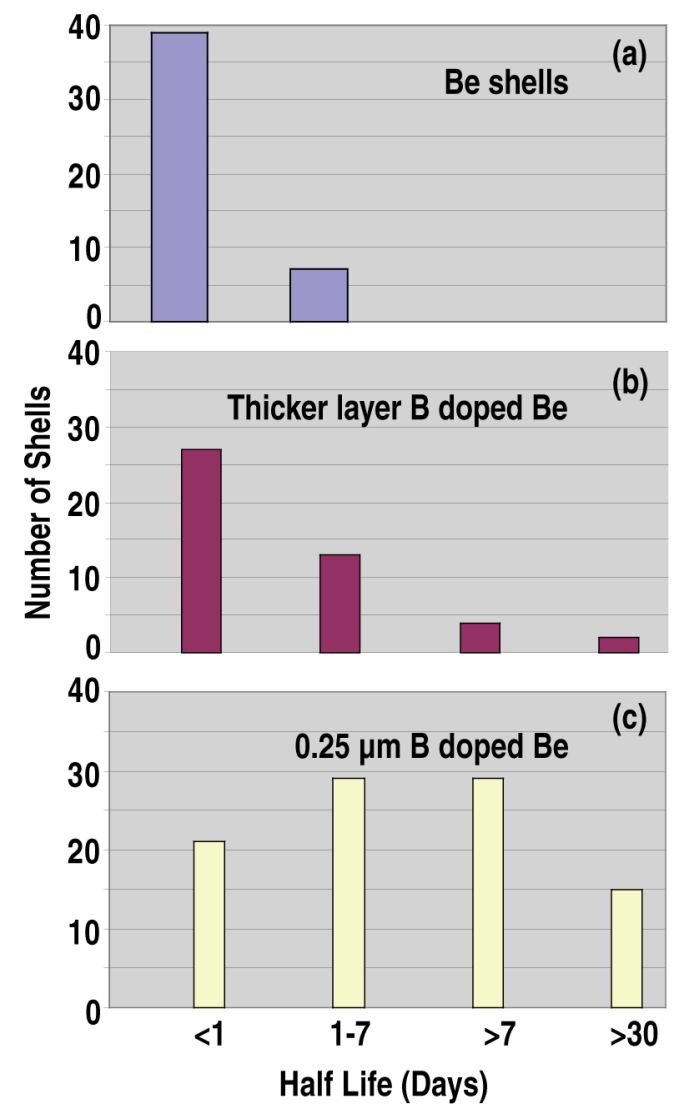

Fig. 4. Plots of measured $\mathrm{D}_{2}$ half-life for (a) pure Be shells, (b) Be shells with thicker $(0.5-6 \mu \mathrm{m})$ B-doped $(\sim 11$ at. $\%$ ) Be permeation barrier layers, and (c) Be shells with $0.25 \mu \mathrm{m}$ B-doped $(\sim 11$ at. \% ) Be permeation barrier layers. The Be shells with $0.25 \mu \mathrm{m}$ B-doped Be layers achieved the longest $\mathrm{D}_{2}$ gas retention half-lives.

To achieve higher gas retention half-lives, one solution is to create a gas permeation barrier. It has been demonstrated that multilayer thin film organic/inorganic composite barrier layers achieved superior water vapor permeation rates by alternating different structured films for organic light emission diode (OLED) applications [13,14]. It was believed that gas permeation through organic/inorganic thin films was dominated by defects. In effect, the multilayer structures should initiate alternating defect structures that will disrupt the interconnected voids and, therefore, reduce the gas permeation rates. The fine striation lines in the Be coatings observed by TEM are imperfections which can cause shell leakage if they connect. Assuming the striation lines are gas leakage pores and that gas leaks through those pores by molecular flow, the gas retention time constant can be estimated as [15] $\tau=V_{s h} / C=\left(4 \pi r_{s h}{ }^{3} / 3\right) /\left[(\pi / 12)(V)\left(d^{3} / l\right)\right]$, where $V_{s h}$ is the shell volume, $C$ is the pore conductance, $r_{s h}$ is the shell radius, $V$ is the average velocity of molecules, $d$ is the pore diameter and $l$ is the length of the pore. Taking a typical Be coating thickness of $50 \mu \mathrm{m}$ and a shell radius of $1000 \mu \mathrm{m}$, a single pore of $200 \mathrm{~nm}$ diameter will result in one day's $\mathrm{D}_{2}$ 
retention half-life, which is roughly the same order of magnitude for a typical Be shell. The gas leakage path in the Be shells may be a combination of numerous fine channels of void defects. Since the average velocity of the molecules is $V=\sqrt{8 k_{B} T / \pi m}$, where the gas retention time constant depends on $\sqrt{T}, T$ is the temperature. Measurements of $\mathrm{D}_{2}$ half-life at room temperature and at liquid nitrogen temperature yield a ratio of half-lives, which agrees with the square root temperature ratio. It supports the assumption of molecular flow gas leakage through the void defects. Since the striation line defects are mostly along the radial direction of the shell, interruption of those defects should cut off the gas leakage path and improve gas retention.

Due to the requirement of low $\mathrm{Z}$ material for the NIF capsules, the choice for the permeation barrier material is very limited. During earlier development work on NIF target production [16-18], B-doped Be coatings achieved smooth surfaces due to the existence of a glassy phase at 11-16 at. \% B. The expectation was that incorporating the B-doped Be would interrupt the columnar grain structure of the Be coatings by forming a permeation barrier for the $\mathrm{D}_{2}$ gas.

To confirm this hypothesis, B-doped Be layers were co-sputtered basing the concentration of $\mathrm{B}$ in $\mathrm{Be}$ on the sputter rates of the two materials. The B-doped Be layers were placed close to the inner surface of the coating due to better surface smoothness [19]. B concentrations from $8 \%$ to $21 \%$ and layer thicknesses from $0.25-6 \mu \mathrm{m}$ were tested as permeation barriers. The resulting half-life data are shown in Fig. 4(b) and (c). Since the current NIF requirement for $\mathrm{D}_{2}$ gas retention half-life is seven days, the data were organized illustrates half-lives below and above the NIF requirement. Figure 4(b) shows the half-lives of the Be shells with thicker B-doped Be layers $(0.5-6 \mu \mathrm{m})$ at 11 at. $\%$. Roughly $10 \%$ of the shells in this group retained half-lives longer than seven days, which is an improvement from the pure Be shells which showed no half-lives longer than seven days. The best results were achieved from the shells with $0.25 \mu \mathrm{m}$ thick B-doped Be layers at 11 at. \% in Fig. 4(c). In this group of shells, 30\%-40\% of the shells exhibited half-lives longer than seven days and $\sim 20 \%$ of the shells consisted of half-lives longer than 30 days. The test structure of the shells with $0.25 \mu \mathrm{m} \mathrm{B}$-doped Be layers consists of two periods of $0.25 \mu \mathrm{m} \mathrm{Be} / 0.25 \mu \mathrm{m}$ B-doped Be layers and $40 \mu \mathrm{m}$ Be. It is interesting to note that the shell half-life did not increase with a thicker permeation barrier. Stress-induced defects are one possible reason for the low gas retention of the thicker Be-doped Be layers. Further studies are needed to fully understand the mechanism.

In Fig. 5(a), a TEM cross-sectional view of a shell with two 11 at. \% B-doped Be layers shows that the two layers are amorphous and interrupted the columnar grain structure of the Be coating. This correlates well with long shell half-lives. However, careful inspection of the B-doped layers at higher resolution reveals that some striation lines extend through B-doped layers [Fig. 5(b)], indicating leakage may still occur through B-doped Be layers. These defects in the amorphous B-doped Be layers may explain the scatter in half-life data. 

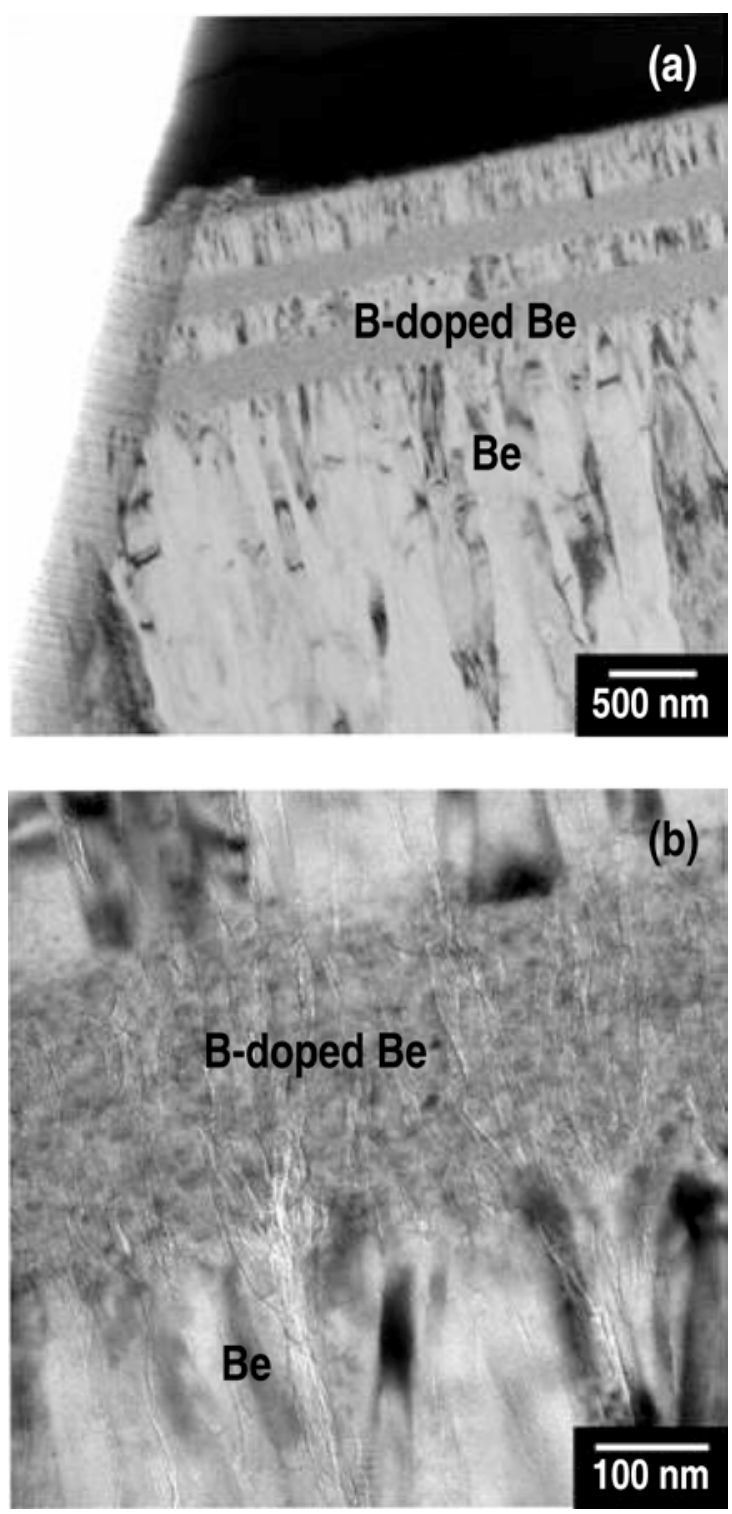

Fig. 5. (a) A cross-sectional TEM image of a Be shell with two $0.25 \mu \mathrm{m} \sim 11$ at. \% B-doped Be layers. The Bdoped Be layers exhibit amorphous structure and interrupt the Be columnar grain structure. (b) A high-resolution TEM image of the B-doped Be layer shows some striation lines penetrating amorphous layer. 



\section{SUMMARY}

Be coatings on plastic mandrels made by magnetron sputtering showed columnar grain structures with void defects. The Be shells with columnar grain structures display short $(<1$ day) $\mathrm{D}_{2}$ gas retention half-lives. A permeation barrier layer consisting of amorphous 11 at. $\%$ $\mathrm{B}$-doped Be layers was incorporated in the coating to improve the $\mathrm{D}_{2}$ gas retention half-lives of the shells. Finally, the Be shells with $0.25 \mu \mathrm{m}$ thick B-doped Be layers displayed the longest $\mathrm{D}_{2}$ gas retention half-lives, with $30 \%-40 \%$ of the shells consisting of $\mathrm{D}_{2}$ retention half-lives longer than seven days. 



\section{REFERENCES}

[1] D. C. Wilson, et al., Phys. Plasmas 5, 1953 (1998).

[2] R. J. Burt, S. F. Meyer, and E. J. Hsieh, J. Vac. Sci. Technol. 17, 407 (1980).

[3] E. J. Hsieh, C. W. Price, E. L. Pierce, and R. G. Wirtenson, J. Vac. Sci. Technol. A 8, 2165 (1990).

[4] R. McEachern, C. Alford, R. Cook, D. Makowcki, and R. Wallace, Fusion Technol. 31, 435 (1997).

[5] R. McEachern and C. Alford, Fusion Technol. 35, 115 (1999).

[6] J. D. Torre, et al., J. Appl. Phys. 94, 263 (2003).

[7] Paritosh and D. J. Srolovitz, J. Applied Physics 91, 1963 (2002).

[8] J. A. Thornton, Annual Review of Materials Science 7, 239 (1977).

[9] M. McElfresh, et al., Fusion Sci. Technol. 49, 786 (2006)

[10] H. Huang, et al., Fusion Sci. Technol. 49, 650 (2006).

[11] E. L. Alfonso, J. S. Jaquez, and A. Nikroo, Fusion Sci. Technol. 49, 773 (2006).

[12] C. C. Roberts, et al., Fusion Technol. 38, 94 (2000).

[13] M. Schaepkens, et al., J. Vac. Sci. Technol. A 22, 1716 (2004).

[14] G. L. Graff, R. E. Williford, and P. E. Burrows, J. Appl. Phys. 96, 1840 (2004).

[15] J. F. O’Hanlon, A User's Guide to Vacuum Technology (John Wiley and Sons, New York, 1980).

[16] A. F. Jankowski, M. A. Wall, and T. G. Nieh, J. Non-Crystalline Solids 317, 129 (2003).

[17] A. F. Jankowski, M. A. Wall, and T. G. Nieh, J. Non-Crystalline Solids 351, 900 (2005).

[18] A. F. Jankowski, et al., Acta Materialia 50, 4791 (2002).

[19] H. W. Xu, et al., Fusion Sci. Technol. 49, 778 (2006). 



\section{ACKNOWLEDGMENTS}

Work supported by the U.S. Department of Energy under DE-AC52-06NA27279, W7405-ENG-36, and W-7405-ENG-48. The authors would like to thank Heather Wilkens for her technical and editorial comments. 